\title{
Developing Automated Bifurcation Angle Measurement Algorithm for Retinal Image Analysis
}

\author{
Kuryati Kipli \\ Faculty of Engineering \\ Universiti Malaysia Sarawak, \\ Kota Samarahan, Sarawak, Malaysia \\ Email: kkuryati@unimas.my \\ Isredza Rahmi A Hamid \\ Department of Information Security, \\ Faculty of Computer Sciences \& \\ Information Technology, \\ Universiti Tun Hussein Onn Malaysia, \\ Johor Malaysia \\ Kumalasari Kipli \\ Faculty of Architecture, Planning and \\ Surveying, Universiti Teknologi MARA, \\ Sarawak, Malaysia
}

\author{
Nur Afifah Ismail \\ Faculty of Engineering \\ Universiti Malaysia Sarawak, \\ Kota Samarahan, Sarawak, Malaysia \\ Nurdiani Zamhari \\ Faculty of Engineering \\ Universiti Malaysia Sarawak, \\ Kota Samarahan, Sarawak, Malaysia \\ Dayang Azra Awang Mat \\ Faculty of Engineering \\ Universiti Malaysia Sarawak, \\ Kota Samarahan, Sarawak, Malaysia
}

\author{
Shamsiah Suhaili \\ Faculty of Engineering \\ Universiti Malaysia Sarawak, \\ Kota Samarahan, Sarawak, Malaysia \\ Rohana Sapawi \\ Faculty of Engineering \\ Universiti Malaysia Sarawak, \\ Kota Samarahan, Sarawak, Malaysia
}

\begin{abstract}
Retina and its vascular network have unique branching characteristics morphology. The abnormalities in the vascular pattern of the retina, such as vessel shape, branching pattern, width, tortuosity, or the appearance of retinal itself, may be associated with the occurrence of retinopathy or cardiovascular diseases. This paper is focus on the development of an algorithm to measure bifurcation angle of the retinal for image analysis. From survey, there is still lack of automation for bifurcation angle measurement. Thus this initial work investigates and proposes the key steps for bifurcation measurement process. The key steps of the proposed method include segmentation of the region of interest (ROI), tracing the vessels that are needed for angle determination and lastly determine the bifurcation angle by using the dot product of the traced boundaries. The results are compared with the manual measurement of the bifurcation angle using quantitative and qualitative measurement. The experimental results show promising result of the proposed method in automating the measurement of bifurcation angle of retinal. Recommendation for room of improvement is also discussed in the paper.
\end{abstract}

Index Terms-Bifurcation angle, segmentation, tracing boundries, image analysis, retinal image, biomedical image processing

\section{INTRODUCTION}

Apart from being an insight to the important parts of the visual system, retinal image can also be used as a reflector of general health of the entire human body. Automated retinal image analysis has recently becoming one of the most important screening tool for an early detection of certain highly risk diseases such as diabetes, hypertension, age related macular degeneration, glaucoma etc. Hypertension retinopathy is one of the diseases that damage the retina and the result of this damage is the loss of vision. This is closely related with high blood pressure[1]-[3].
The abnormalities and changes of vascular pattern are observed as this is the main factor to identify these diseases [3]. The features that are obtained can assist in detecting, diagnosing or evaluation of ocular or systematic diseases. In this work, features that needed to be extracted are the vessels diameter, the branching angle, the bifurcation angle and the vessels gap as shown in Fig. 1(a)-(d).

Vessels diameter is the measure of the width of the vessel. Branching angle is the angle between the main vessel and one of its branches. Bifurcation angle is the angle between two branch vessels at which the main vessel splits into two vessels. Lastly, vessel gap is the discontinuity of the vessel at certain place [4].

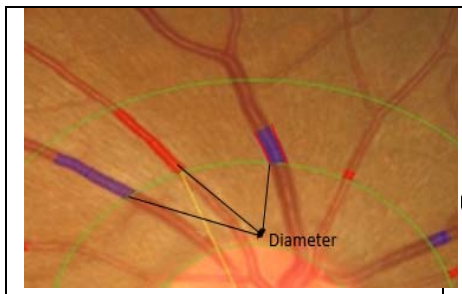

(a)

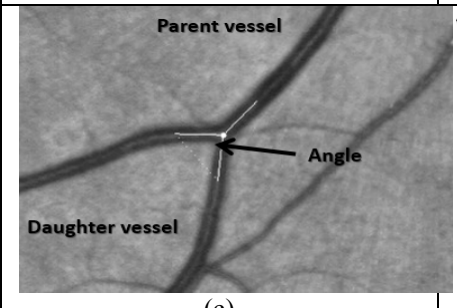

(c)

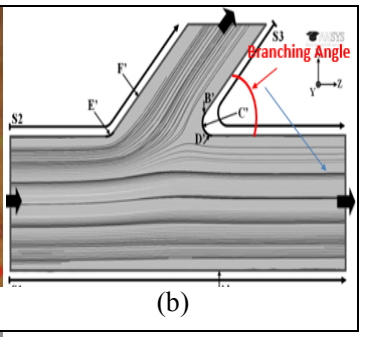

(b)

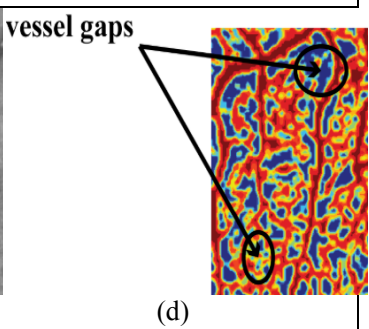

(d)
Fig. 1: (a) Vessels Diameter (b) Branching angle (c) Bifurcation Angle (d) Vessels Gap [4]

The main focus for this paper is on the development of an image processing technique for bifurcation angle measurements. At the same time the paper also investigate the feasibility of using retinal blood vessel bifurcation angle as marker for hypertension detection. 